\title{
Pessoas com Deficiência e Escola: principais mudanças na experiência italiana
}

\author{
Giovanna Di Pasquale \\ Marina Maselli' \\ 'Universidade de Bologna - Itália
}

RESUMO - Pessoas com Deficiência e Escola: principais mudanças na experiência italiana. O texto analisa a experiência italiana de inclusão escolar das pessoas com deficiência, destacando os dispositivos normativos que estabeleceram a transição para um sistema que tem a inclusão como a diretriz fundamental para toda a educação nacional desde os anos de 1970. $\mathrm{Na}$ análise, mostra-se a complexidade de instituição de uma política que contempla: a colaboração necessária entre os vários profissionais, a ligação família-escola, a construção de percursos personalizados integrados ao planejamento coletivo para a classe, a formação de professores, a orientação escolar e profissional. Considera-se a educação como parte de um plano de vida da pessoa com deficiência e a construção de seus modos de participar ativamente da vida social.

Palavras-chave: Educação Especial. Deficiência. Inclusão Escolar. Política Educacional.

ABSTRACT - Disabled People and School: major changes in the Italian experience. In this paper, we analyze the Italian experience in educational inclusion of disabled people. In the study, we highlight the regulatory provisions that established the transition to a system in which, since the 1970s, inclusion has been the fundamental guideline for all national education. The analysis shows the complexities of establishing educational policies comprising the necessary collaboration among different professionals, the connection between family and school, the construction of personalized, integrated ways for the collective planning of the classes, the teachers training, and the academic and professional orientation. Education is considered part of a life plan and the construction of an active participation in social life of disabled people.

Keywords: Special Education. Disabilities. School Inclusion. Educational Policy. 


\section{Um Caminho para a Inclusão}

O objetivo do presente texto é refletir sobre o quadro atual da inclusão escolar de pessoas com deficiência na Itália, sobre as características que atualmente definem esse processo e sobre as perspectivas que abordam o tema. Tais metas implicam, inevitavelmente, retomar, ainda que em modo sintético, as referências normativas que ao longo do tempo consagraram a mudança de um sistema separado - escola comum e escola especial - para um modelo único que tem sido reconhecido como referência, para além das fronteiras nacionais, e que organiza as políticas de inclusão educacional e social no contexto italiano. Analisar tais políticas a partir de um ponto de vista histórico pode ajudar a reconhecer a perspectiva de continuidade, o que ao longo dos anos tem se confirmado como estável e recorrente, assim como as possíveis diferenças entre as expectativas e os resultados obtidos.

A partir de uma perspectiva histórica, por outro lado, também é possível identificar como os diferentes períodos e modelos de referência não se esgotam em uma sucessão mecânica, e sim coexistem em várias dimensões de acordo com os momentos e com as situações. De fato, o processo de inclusão escolar se desenvolveu de forma decidida, mas, ao mesmo tempo, condicionada e descontínua. A Itália é o país que assumiu de forma mais radical a diretriz associada à inclusão escolar ao logo de sua história recente, fazendo com que deixassem de existir alternativas diferentes dos espaços do ensino comum, como as escolas especiais e as classes especiais'. Apesar disso, as condições de desenvolvimento extremamente heterogêneas do território italiano, os altos e baixos de políticas de apoio ao sistema de ensino como um todo e a retirada dos recursos públicos tiveram um impacto significativo sobre as condições reais da tradução dos princípios orientadores em práticas educativas cotidianas que contribuíram para delinear um quadro heterogêneo, desigual, que apresenta situações de excelência e de boa qualidade e outras certamente muito mais críticas e merecedoras de atenção.

Ao considerarmos o ponto de vista histórico, podemos dizer que o interesse pela educação de alunos com deficiência é relativamente recente no contexto italiano: a escolaridade obrigatória estendia-se de modo efetivo somente aos cegos e surdos, de acordo com a terminologia da época, após a Riforma Gentile de 1923.

Um pouco mais tarde, a educação especial incluiu aulas diferenciadas para os alunos com atrasos leves que estudavam em escolas regulares, passando a investir em escolas especiais para os surdos, cegos $e$ mentalmente anormais, as quais eram separadas e distintas.

Para os casos considerados mais graves, eram oportunizadas instituições especiais, em que as pessoas com deficiências assim consideradas viviam separadas de suas famílias e do contexto de origem e, de forma mais geral, afastadas das experiências da vida cotidiana. Do período anterior à Segunda Guerra Mundial até meados de 1960, a lógica 
dominante era a da separação, e a ideia de deficiência como uma doença continuava forte e associada amplamente à medicalização como alternativa de atendimento.

No final da década de 1960, a exigência de mudanças começou a ser forte e inevitável;

O movimento estudantil, o protesto contra o autoritarismo e uma forte mobilização político-ideológica criaram um clima favorável à abolição das instituições totais e à libertação de pessoas vulneráveis, tratadas, como declarado, de modo separado, especial e segregante (D’alonzo; Ianes, 2007, p. 187).

Um papel fundamental foi desempenhado pelas associações de famílias de pessoas com deficiência que, nesse momento crucial, reivindicaram direitos e apoiaram ativamente propostas inovadoras. Além disso, e sobretudo em alguns aspectos, muitos atos inovadores e democráticos interferiram na escola: os experimentos do Movimento de Cooperação Educativa (MCE), as experiências de educação ativa, as iniciativas de Don Milani e a Escola de Barbiana.

Neste contexto escolar, muito envolvido na tensão renovadora, iniciou-se a inserção de alunos com deficiência em classes comuns do ensino regular sob a pressão dominante de indicações normativas que tiveram a função de diretrizes pioneiras.

A Lei n. 118/1971 proporcionou a inclusão de alunos com deficiência considerada leve em classes comuns no ensino regular obrigatório, sem qualquer referência à educação especial, ao potencial de desenvolvimento ou aos recursos a serem utilizados. Essa lei considerou principalmente a oportunidade de socialização regida por uma lógica de adaptação unidirecional por parte do aluno com deficiência e de sua família.

Em 1975, a Comissão Especial presidida pela senadora Franca Falcucci criou um relatório detalhado, no qual também podemos encontrar a intenção de alterar o funcionamento da escola para melhor contemplar os alunos com deficiência.

As primeiras mudanças propostas pelo relatório referem-se à implementação de tempo integral e à redução do número de alunos em uma classe que comporta a presença de uma pessoa com deficiência. Mesmo assim, a integração escolar era prevista apenas para pessoas com deficiência leve (Miele, 2013, p. 2).

A abolição das classes especiais e a generalização do princípio de integração ${ }^{2}$ foram obtidas com a Lei n. 517/1977, esta é um marco realmente importante na trajetória da educação inclusiva, que identifica modelos didáticos flexíveis que possibilitem formas de inclusão escolar transversais, experiências interclasse ou atividades organizadas em grupos de alunos e confiadas a educadores especializados. 
Existe uma ampla série de medidas legislativas posteriores à promulgação da Lei 517/77, as quais tiveram a finalidade de completar a legislação sobre o assunto em questão, tanto para o setor sociossanitário quanto para aquele voltado mais especificamente para a inclusão escolar.

A Lei n. 104, de 5 fevereiro de 1992, Lei de Bases para a assistência, a integração social e os direitos das pessoas com deficiência, reúne e integra estas medidas legislativas, tornando-se o ponto de referência normativo da inclusão escolar e da inclusão social de pessoas com deficiência. Em 1994, com a promulgação do Decreto Presidencial de 24 de fevereiro, foi definido o papel auxiliar de especialista técnico, que os serviços de saúde devem ter no âmbito das escolas envolvidas nos processos de inclusão. Esses dois atos normativos regem ainda a prática cotidiana da inclusão escolar.

Por uma questão de integridade do quadro normativo de referência, é necessário mencionar também a Lei n. 328, de 8 novembro de 2000, Lei de Bases para a implementação do sistema integrado de medidas e serviços sociais, um dispositivo importante para a implementação de medidas no âmbito da educação, dos serviços sociais e da reconciliação entre as diferentes áreas do conhecimento postas em jogo pela trajetória da inclusão.

Adicionamos, ainda, referências a um dispositivo de síntese $D i$ retrizes para a integração escolar de alunos com deficiência, publicado em 4 de agosto de 2009 pelo Ministério da Educação, Universidade e Pesquisa (MIUR). As linhas norteadoras desse documento reúnem:

Um conjunto de diretrizes que visa, considerando a autonomia das escolas e a legislação aplicável, melhorar o processo de integração dos alunos com deficiência. Tais diretrizes foram desenvolvidas com base em uma análise compartilhada entre gestores, especialistas do MIUR e com a participação das associações de pessoas com deficiência. Destinam-se a levantar o assunto em questão, o qual é ponto básico da tradição pedagógica da escola italiana, que assim deve permanecer mesmo em tempos de mudança e de transformação do sistema de educação e formação nacional (Itália, 2009, p. 1).

Como pode ser visto por uma sucessão de orientações legais, o percurso da inclusão dos alunos com deficiência permite revelar modelos implícitos ou explícitos de escola a que se faz referência, no espaço de algumas décadas:

- Uma escola na qual há clara distinção entre alunos com deficiência e outras pessoas, considerando a inclusão possível quando um aluno com deficiência pode acompanhar, de alguma forma, o programa dos outros;

- Uma escola na qual se reconhece que alguns dos alunos que normalmente frequentam a instituição de ensino requerem estra- 
tégias educacionais específicas, incluindo nesse grupo os alunos com deficiência;

- Uma escola na qual é possível reconhecer e aceitar as diferenças individuais, organizando-se para fornecer respostas adequadas.

Mais uma vez, a presença de pessoas com deficiência interfere, com vantagens, na tomada de decisões mais claras e orientações básicas que têm implicações amplas e generalizadas, justamente porque as mudanças essenciais que retomamos até agora fazem referência a alguns modelos de interpretação da escola que se manifesta na sua capacidade de acolher e na comparação com as diferenças estruturalmente presentes na sala de aula.

Quando nos interrogamos sobre os alunos com deficiência encontrados na escola italiana, identificamos que os números dessas matrículas têm aumentado. De acordo com as indicações do Ministério da Educação (Ministero dell'Istruzione dell'Università e della Ricerca), de um total de matrículas de 7.300.000 alunos, 215.590 foram identificados como alunos com deficiência em 2012. Esses indicadores mostram um aumento de $2,9 \%$ em relação às matrículas no ano precedente. $\mathrm{O}$ aumento torna-se ainda mais significativo quando comparamos esses indicadores com as matrículas de alunos identificados como alunos com deficiência em 2001, pois estes representavam um contingente de 126.994 matrículas.

Nesse sentido, as escolhas italianas relativas à designação dos alunos são atualmente influenciadas por aquelas que aparecem no cenário internacional desde 2007 e que, por meio da classificação proposta pela OCDE e aprovada pela Comissão Europeia com base em um Instrumento do CRELL - Centre for Research on Lifelong Learning-, conferiram grande relevância ao conceito de Necessidades Educativas Especiais $^{3}$ (NEE). Esse investimento conceitual tem grandes impactos no processo de identificação dos sujeitos. De acordo com esta classificação, os alunos são divididos em três categorias:

- Alunos com deficiência (categoria A): incapacidade ou deficiência em termos de cuidados de saúde, que derivam de limitações orgânico-funcionais atribuíveis a deficiências ou doenças orgânicas (deficiência sensorial, motora ou neurológica). Na Itália, as confirmações da presença de deficiência pertencem a esta categoria;

- Alunos com dificuldades (categoria B): dificuldades emocionais e comportamentais ou Transtornos Específicos de Aprendizagem (TEA, como a dislexia). Na Itália, essa condição foi também inserida, em nível normativo, nos últimos tempos por meio da Lei n. 170 de 2010, sobre Transtornos Específicos de Aprendizagem (TEA);

-Alunos com desvantagens (categoria C): dificuldades associadas ao ambiente socioeconômico, cultural e sociolinguístico de origem. 
O destaque conferido ao conceito Necessidades Educativas Especiais (NEE) retoma, com coerência, a ênfase evidenciada, em nível internacional, relativa ao modelo CIF (Classificação Internacional de Funcionalidade, Incapacidade e Saúde), da OMS (Organização Mundial da Saúde). Um modelo dinâmico de leitura da saúde e da doença, no qual a deficiência está associada à interação complexa de múltiplos fatores. Na verdade, essa proposta é relacionada aos níveis de atividade e de participação possíveis para a pessoa com deficiência a partir de uma perspectiva em que os âmbitos biológico, psicológico e social são considerados intimamente ligados e interdependentes.

É importante enfatizar como justamente essa perspectiva vinha sendo abordada desde a Convenção da ONU sobre os Direitos das Pessoas com Deficiência (3 de dezembro de 2006) que, já no Preâmbulo, reconhece a deficiência como um conceito em evolução, como o resultado da interação entre pessoas com incapacidades e barreiras comportamentais e ambientais que impedem a sua inclusão plena, assim como a efetiva participação na sociedade com base nas reais oportunidades de igualdade com os demais.

\section{Um Desafio Coletivo: uma escola de qualidade para todos}

A qualidade da inclusão escolar das pessoas com deficiência, mesmo quando considerada em um momento histórico preciso e definido, em um contexto territorial como o italiano, implica necessariamente o esforço de compreender esse contexto em termos de orientação conceitual e em relação às práticas e atividades compatíveis com essa orientação.

A partir deste quadro de significados compartilhados, surge também um objetivo mais amplo, no qual o sistema de ensino e todas as instituições envolvidas encontram-se empenhados: a passagem evolutiva de um processo unidirecional de adaptação do aluno com deficiência à escola, à inclusão concebida como uma capacidade de dar respostas diferenciadas, individualizadas e personalizadas no âmbito de um sistema de educação e formação único e compartilhado.

Nesta passagem evolutiva, o conceito de inclusão é colocado sobre uma via de dupla compreensão. A primeira concentra-se em uma ideia de inclusão que reafirma a necessidade de pessoas com deficiência, jovens e adultos, de viver experiências no contexto da normalidade.

Sentir-se normal no sentido de ser alguém com o mesmo valor, mesmo sendo profundamente diferente. Essa necessidade de normalidade não nega a diversidade ou a necessidade especial de deficiência ou de patologias específicas, apenas as coloca em uma necessidade profunda e essencial de normalidade, valor e dignidade (Ianes, 2006, p. 12). 
$\mathrm{O}$ acesso a ambientes caracterizados pela normalidade das ocasiões tem como significado prioritário o respeito das necessidades de identidade e pertencimento, comum a todos os seres humanos, independentemente de sua condição existencial e social.

A segunda via compreensiva indica que a necessidade de normalidade vincula-se à valorização de que os processos de inclusão reconheçam a complexidade e a especificidade das necessidades educacionais dos alunos que se encontram em situação de desvantagem associada à deficiência. Não se trata, portanto, de negar a presença de dificuldades extremamente diversificadas na sala de aula, em nome de uma abordagem ideológica que transformaria todos em normais, mas de acolher de maneira clara a condição da presença, cada vez mais evidente e generalizada, de circunstâncias específicas e originais relativas à aprendizagem de um número sempre crescente de alunos.

Por outro lado, a predisposição de muitos serviços à coletividade (transporte, acesso a locais públicos) é baseada na suposta normalidade da população como um todo e quase sempre ignora a verdadeira atenção a esta complexidade, que se refere a diferenças essenciais, incluindo a deficiência. A instituição escolar pode correr esse risco, e, neste sentido, a introdução de um conceito como o de Necessidades Educativas Especiais implica exatamente a consciência de que a população escolar é estruturalmente heterogênea e marcada por modos, estilos e características diferentes.

A busca por um diálogo entre normalidade e especialidade torna-se então uma condição essencial para construir um programa destinado a fazer tudo o que é necessário para o desenvolvimento máximo das potencialidades dos alunos com deficiência, sendo esta a meta final pela qual se deve trabalhar. Isso significa pensar em termos de efeitos no sistema educacional e organizacional da presença, em um percurso comum e unificado, de atividades e propostas personalizadas e individualizadas. Um percurso direcionado que se constrói levando em conta todas as habilidades, conhecimentos e papéis das partes interessadas.

A participação ativa e responsável de todos passa a ser vista como uma das condições para se construir a qualidade:

Outro significado forte é o de uma responsabilidade conjunta de muitos agentes de processos educativos e o de pesquisa e implementação de um quadro o mais amplo possível de recursos escolares e extraescolares. Assumir a responsabilidade conjunta significa tomar medidas em um projeto de integração sem delegar a outros em nome da suposta dificuldade e complexidade das necessidades. Um dos principais aspectos de uma integração 'boa o suficiente' acaba por ser a participação coletiva em práticas inclusivas '[...] que não são delegadas ao pessoal especializado’ (Ianes, 2006, p. 47). 
Na construção deste tipo de participação coletiva, o ponto central consiste na utilização de recursos especializados, incluindo o professor especialista ou, em uma linguagem mais frequente, o professor de apoio. A expressão professor de apoio ${ }^{4}$ surgiu já no fim dos anos 70 (Circular Ministerial n. 199 de 1979), em uma circular que define esse profissional como um professor titular, no sentido de um docente com plenas responsabilidades, e não como um elemento adicional. Nessa circular se afirma que toda a comunidade escolar deve estar envolvida em tal apoio. Nesse sentido, indica que "[...] para o sistema escolar, tem se destacado a necessidade de figuras especializadas, mas que não devem ser fonte de separação" (Itália, 1995).

Em conformidade com essa finalidade dessa ação coletiva, já retomada e acentuada muitas vezes, a meta atual dos recursos especializados em favor da inclusão é a qualificação, a fim de aumentar a competência do sistema, de trabalhar de modo estrutural e não transitório, por que,

Se a presença de uma pessoa com deficiência é vista como um evento excepcional, a estruturação da escola como um todo não produz uma mudança substancial capaz de permitir, no futuro, o acolhimento (não mais emergente) de outra pessoa com deficiência (Canevaro; Mandato, 2004, p. 83).

A inclusão de qualidade está ligada, portanto, ao crescimento de uma qualificação de competências tanto em termos de estrutura quanto do exercício da responsabilidade pessoal; não é um aspecto particular, mas um desafio coletivo que põe em questão todo o sistema escolar em sua capacidade de atender às exigências e necessidades de formação dos indivíduos dentro de uma estrutura de governança de políticas. Com relação à presença dos professores de apoio na escola italiana, de acordo com os dados oficiais ministeriais, tem ocorrido um aumento numérico, sendo que no ano escolar 2010/2011 esse total era de 96.089 docentes especializados, o que equivale a $12 \%$ do total de professores da educação que envolve as etapas precedentes à formação universitária.

\section{Quais as Dimensões para a Inclusão de Qualidade? Indicadores e boas práticas de ensino}

Uma inclusão que supera a si própria e constantemente se compara com a complexidade e a diferença, sempre presente no ambiente escolar e educacional, é uma inclusão que interroga, que segue em busca de indicadores concretos em relação aos seus componentes, às áreas onde se desenvolve a qualidade e àquelas que, como outra face da mesma moeda, é possível ocultar os aspectos críticos.

Depois de várias décadas de realização dos percursos de inclusão, foi inserida uma fase importante de análise da experiência, que resultou em ações de releitura, monitoramento e avaliação. Estudos e pesquisas realizados na Itália a partir do final dos anos 1990 produziram 
reflexões nesta área de pesquisa, as quais, na busca de indicadores de qualidade, encontraram pontos de convergência e de inovação na releitura das práticas.

Um indicador é de fato algo que representa, é um sinal, uma estrutura conceitual que procura resumir do modo mais próximo e significativo possível uma determinada dimensão da realidade. Trabalhar com indicadores requer a posse de capacidades não só técnicas, mas também reflexivas, de interpretação contínua e de diálogo com a realidade, especialmente se queremos entender as dimensões desta realidade ligadas à diferença e à inclusão.

Sob este ponto de vista, a tradução dos indicadores em números também assume um peso e um significado diferentes. Para algumas dimensões da inclusão, há indicadores passíveis de serem expressos em números, para outras, não. Isso não significa que apenas as primeiras são importantes ou têm maiores méritos, mas simplesmente que a realidade da inclusão é demasiado complexa para ser reduzida a um único tipo de instrumento ou a um único método de investigação.

A principal função de um indicador é tornar possível uma especificação operacional, no que diz respeito a conceitos de natureza geral. Termos como integração, inclusão, bem-estar, acolhimento representam conceitos extremamente amplos que se referem implicitamente a uma série de fatores e itens específicos que precisam ser identificados se quisermos traduzir esses conceitos em dimensões operacionais relacionadas à experiência.

Vejamos, então, mais precisamente, como se constitui um processo designado inclusão escolar. Quais as dimensões de configuração de um campo específico? Em que modo as experiências, as pesquisas e os estudos conduzidos indicam pontos cruciais para avaliar o atual estado dos processos de integração e inclusão.

A primeira dimensão refere-se à Corresponsabilidade educacional em relação ao aluno com deficiência e o grau de colaboração entre os profissionais.

Para reduzir o máximo possível o risco de exclusões degradantes e de delegação de responsabilidade, o professor de apoio deve exercer uma corresponsabilidade educacional que ocorre principalmente por meio de uma colaboração complementar, consistente e avaliável entre os profissionais envolvidos, dentro e fora da escola. As condições para a atividade eficaz de uma equipe são numerosas e se situam em vários níveis. Para os alunos com deficiência essas condições estão diretamente relacionadas com aquelas consideradas essenciais para uma educação de qualidade, "[...] uma relação baseada na confiança mútua, a percepção de uma comunhão de status, uma experiência suficientemente longa das modalidades de trabalho em conjunto, uma ampla capacidade de instrumentos de avaliação comuns e eficazes [...]" (Tilstone, 2003, p. 20). 
Para que seja traduzido em prática cotidiana, tudo isso requer: reuniões contínuas durante o ano todo para a concepção e avaliação comum; a presença simultânea nas reuniões do professor de apoio e das figuras educacionais complementares (quando houver); a participação nos momentos de programação individualizada de todos os atores sociais envolvidos com componentes didáticos e educacionais.

A segunda dimensão, intimamente relacionada com a anterior, é a do Uso de recursos especializados em função de um aumento generalizado de competências.

Em estreita ligação com o tema da colaboração entre os profissionais, deve haver espaço para uma reflexão sobre o papel do recurso especializado ou do apoio. É por meio da percepção que o professor possui acerca de seu próprio papel, e do uso que a escola como um todo é capaz de fazer em suas práticas, que realmente entramos em contato com os modos de ocupar-se do aluno com deficiência. Trabalhar para aumentar a capacidade de inclusão do sistema de ensino significa "[...] passar da lógica do apoio para a lógica do apoio compartilhado" (Dovigo, 2007, p. 34).

Este é um importante passo conceitual, articulado em uma série de ações precisas e associadas:

- Identificação de uma função instrumental relativa à inclusão e individualização de tarefas explícitas e compartilhadas de coordenação, e não de delegação de responsabilidades;

- Criação de um Grupo de Trabalho de Instituto/Escola (como previsto pela Lei de Bases), que preveja a presença de múltiplas funções profissionais na lógica da responsabilidade estável e compartilhada em relação à deficiência;

- Garantia para todos os envolvidos no Grupo de Trabalho de participar de todas as reuniões de modo sistemático;

- Participação de todos os professores em cursos de formação e oportunidades de estudo sobre os tipos específicos de deficiência; - Criação de formas de documentação dos métodos e dos resultados, assim como a individualização das modalidades de uso relacionadas para todos os envolvidos;

- Criação de oportunidades de formação ampliada e continuada sobre as estratégias para a inclusão de todos os alunos com Necessidades Educativas Especiais.

Uma terceira dimensão está baseada na ideia de que a inclusão escolar é constituída pela Relação entre programação comum, atividades personalizadas, percursos individuais. O PEI, Plano de Educativo Individualizado, é o instrumento principal exigido pelas diretrizes legais, no contexto italiano, para orientar o caminho do aluno com deficiência na escola. $\mathrm{O}$ adjetivo individualizado assinala com clareza como a atenção deve estar dirigida ao indivíduo e ao seu plano preciso de aprendizagem 
que, no entanto, ocorre e deve ocorrer em um contexto de comunidade e de relações integradas.

O plano educativo inclui o diagnóstico funcional, o perfil dinâmico-funcional, a lista de atividades educativas organizadas em função das necessidades educativas específicas do aluno e, por fim, os critérios de avaliação adequados à situação pessoal. No âmbito do PEI, são concebidas e avaliadas as situações educativas comuns, personalizadas e eventuais atividades individualizadas. Essa busca pelo equilíbrio é absolutamente crucial, pois “[...] uma ênfase excessiva nas necessidades individuais tende, de fato, a marginalizar o aluno, retirando o sentido da sua permanência na classe" (Celi, 2000, p. 125).

Deve-se colocar em diálogo a necessidade de individualização e relacionamento/socialização, não só porque todos estes requisitos devem contemplar o percurso de vida do aluno com deficiência, mas também para as implicações em termos de crescimento e aprendizagem que se referem a todos os alunos,

Não podemos renunciar aos benefícios da normalidade, nem renunciar aos benefícios de uma especialidade técnica, portanto temos de manter as duas juntas, superando uma aparente incompatibilidade, em uma dialógica, diria Morin, que mantenha unidas as duas dimensões, ou o melhor delas. É o que chamaremos de normalidade especial (Ianes, 2006, p. 9).

De acordo com os documentos destacados ao longo do texto, quando consideramos as ações concretas, a construção de um PEI implica:

- ações para a coleta de dados e informações úteis (observação sistemática, reuniões iniciais e periódicas com a família e com os técnicos, atividades de acolhimento);

- organização flexível e articulada (aulas abertas, grupos de nível, trabalho em pares, grupos de interesse, uso de laboratórios, aprendizagem cooperativa, uso de tutoria);

- estratégias para facilitar a aprendizagem. A presença de um aluno com deficiência torna-se a força propulsora para a ativação de mudanças que alteram o trabalho dentro da sala de aula, e tem também um impacto maior sobre as escolhas educacionais tomadas.

Há uma tendência a considerar como necessária a referência à avaliação concebida como ferramenta inevitável para a melhoria dos projetos individuais e da escola, portanto, a avaliação como parte integrante do PEI. A avaliação não deveria ser apenas o teste contínuo e final sobre o que foi construído em relação à aprendizagem, mas deveria envolver também a atenção dirigida aos progressos realizados nas áreas de autonomia, comunicação, relacionamento. Nessa perspectiva, trata-se de uma avaliação que apresenta modalidade participativa e proporciona formas de auto avaliação também por parte dos alunos, 
uma avaliação que também verifica se a intervenção do apoio torna-se menor na medida em que são reafirmadas as habilidades dos alunos. Ainda no âmbito da dimensão da Relação entre a programação comum, as tarefas personalizadas, os percursos individualizados, cabe fazer um esclarecimento sobre os espaços, os espaços físicos onde o aluno com deficiência trabalha.

Um espaço inclusivo deve ser pensado de modo articulado e modular: permite que todos possam ficar juntos em sala de aula e ter um papel importante e, ao mesmo tempo, proporciona a presença de espaços separados, tais como laboratórios onde são feitos trabalhos em grupos (Canevaro, 1999, p. 25).

Esta reflexão, aplicada ao ambiente escolar, implica um grande esforço para garantir que até mesmo o espaço seja compreendido como uma instância de apoio e desempenhe uma pluralidade de funções por meio da presença de:

- espaços específicos e personalizados;

- espaços comuns (sala de aula, refeitório...) organizados de forma

flexível de acordo com as respostas das pessoas;

- espaços que medeiem e suportem as relações em grupos pequenos, como laboratórios.

A inclusão escolar de boa qualidade é um processo composto e compartilhado, que afeta as funções e deveres de todas as pessoas envolvidas, em primeiro lugar, e de modo direto, os professores, demais profissionais da escola e a família.

A colaboração entre a escola e a família é a quarta dimensão que examinamos.

A participação das famílias dos alunos com deficiência no processo de integração se dá por meio de uma série de formalidades exigidas por lei. De fato, de acordo com o artigo 12, parágrafo $5^{\circ}$ da Lei no $104 / 92$, a família tem o direito de participar na formulação do Perfil Dinâmico Funcional e do PEI, bem como de suas avaliações (Itália, 2009, p. 12).

É evidente que um dispositivo normativo não é suficiente para tornar a colaboração entre a escola e a família tangível e produtiva; é necessário que as relações entre estas duas áreas ocorram não apenas na lógica do apoio às famílias em relação às atividades escolares e ao processo de desenvolvimento do aluno com deficiência, mas considerando uma participação ativa associada a um reconhecimento desses sujeitos como competentes.

A família representa um ponto de referência essencial para a inclusão da pessoa com deficiência, seja como fonte de informações valiosas, muitas vezes únicas, seja como interlocutor importante de um processo que, a partir do Plano de Educativo Individualizado, se desenvolve em um verdadeiro Projeto de vida da pessoa com deficiência. 
A experiência italiana sobre essa temática tem mostrado que o envolvimento da família deve ser efetivo, como dizem aqueles que trabalham diariamente no interior da escola,

O papel central da pessoa acompanha o papel central de sua família. Isso representa o primeiro e mais importante agente educacional de habilitação e reabilitação com o qual as instituições e seus funcionários devem ser capazes de construir um relacionamento de colaboração. Isto significa que para qualquer planejamento em relação à pessoa/ao aluno, é necessário obter o consentimento real da família (Provincia di sondrio, 2007, p. 2).

A busca por um consenso não significa que a escola deve abdicar do seu papel na educação e formação, mas sim levar a sério a construção de um diálogo com a família que tenha como meta uma aliança, evitando a confusão de papeis, como bem apontado pela reflexão proposta por Andrea Canevaro,

É um elemento importante que caracteriza a capacidade de colaborar para as funções e para as competências, evitando as situações maleáveis, pouco claras, quando, mais que colaborar para as competências, criam-se cumplicidades. Não a cumplicidade, palavra que inclui alguns elementos de ambiguidade lamentáveis, mas sim a colaboração para as competências. O resultado é uma atribuição de peso inferior para as dimensões pessoais do caráter, da personalidade nas colaborações, investindo, ainda mais, na capacidade de atender às necessidades de funcionamento de uma instituição. E isso coloca a responsabilidade das instituições a serviço do projeto, sem que a ansiedade de criação negligencie os procedimentos institucionais. Paradoxalmente, também acaba melhorando os aspectos das relações (Canevaro, 2013, p. 1).

A partir de todas as reflexões apresentadas, podemos resumir como a busca pela qualidade no processo de inclusão escolar exige comprometimento e energia para superar as barreiras de ordem cultural, política, social, além das barreiras estruturais e organizacionais. Comprometimento e energia que, para terem resultados eficazes, apontam para a necessidade de um alto Nivel de coordenação e integração entre as pessoas de dentro da escola e as figuras técnicas externas, além do uso de recursos extracurriculares. E esta é a quinta dimensão que consideramos.

Apenas um trabalho interinstitucional consistente e contínuo pode facilitar a participação, coordenação e integração das competências e dos recursos das partes envolvidas, congregando a escola, as autoridades e agências de saúde locais, assim como as famílias.

E é com base nessas ponderações que a Lei 104/92 identifica a necessidade de formalizar, por meio de acordos de planejamento, propos- 
tas de interação e coordenação dos serviços educacionais, dos serviços de assistência social e de saúde, os quais são necessárias para uma boa qualidade de inclusão escolar e social de alunos com deficiência.

As boas práticas neste aspecto particular indicam os seguintes elementos construtivos:

- A presença no plano de oferta de formação de acordos ou contratos com entidades externas para a criação de uma rede com maiores recursos para ajudar os alunos;

- A criação de comparações e testes entre profissionais de saúde, comunidade educativa, operadores e centros privados externos (não só em conformidade com as diretrizes legais, mas também em relação com as necessidades emergentes, com um ambiente colaborativo), não apenas uma programação regular durante o ano, mas também mediante solicitações;

- A implementação de iniciativas relacionadas com a inclusão escolar dos alunos com deficiência promovida conjuntamente pelas escolas e serviços (de informação, sensibilização, atualização, pesquisa, atividades inovadoras) de forma sistemática;

- A criação de projetos especiais em que todos os alunos da classe estejam envolvidos em atividades de laboratório que utilizem estruturas e conexões externas à escola;

- A criação de percursos integrados que alternem entre escola/ território para os alunos com deficiência que apresentam necessidades específicas, ou que se preparam para sair da escola.

\section{Supervisão da Qualidade: pontos críticos e de atenção}

O principal objetivo da inclusão escolar é uma meta nunca atingida em modo definitivo e estável. De acordo com os aspectos expostos ao longo do presente texto, a inclusão efetiva das pessoas com deficiência nas escolas e na sociedade é um processo complexo e detalhado, que requer a existência e a disponibilidade de uma pluralidade de figuras cujas habilidades, conhecimentos e histórias devem dialogar e se complementar.

O reconhecimento dos respectivos papéis e responsabilidades, a integração de competências, a coordenação das ações são todas condições indispensáveis para assegurar a programação coerente das intervenções.

A qualidade da inclusão escolar, assim como a qualidade do ensino, não poderia estar associada a parâmetros absolutos, mas, deveria ser concebida como um conceito - qualidade-definido no contexto dos processos históricos e das negociações. Supervisionar a qualidade significa manter um foco constante sobre todos os aspectos mencionados até o momento, aspectos sem os quais é provável que todo o processo tenda à estagnação ou retroceda. Supervisionar a qualidade significa 
também ativar os caminhos de pesquisa que permitem fazer um balanço da situação de um percurso de décadas.

Os balanços tendem a ser sempre parciais e provisórios. No entanto, ajudam a focar os pontos fortes, bem como alguns pontos críticos do modelo atual. Com base nessas premissas, passamos a indicar alguns desses pontos, a partir da análise de uma pesquisa que teve muita importância na Itália e que dá ênfase a certos aspectos sobre os quais devemos manter voltada nossa atenção (Associazione Treellle, 2011):

- a relação entre o aluno com deficiência e o professor de apoio ou especializado. A forte ênfase na figura do professor de apoio que caracteriza o modelo italiano pode levar, em alguns casos, ao risco de dar origem a situações em que se coloca uma ênfase excessiva sobre a tarefa do professor de apoio e sobre o número de horas atribuídas, reduzindo a oportunidade de identificar nele um recurso para toda a classe e criando, paradoxalmente, fenômenos que delegam a ele situações de isolamento, tanto do aluno quando do próprio professor. Para isso, considera-se importante não esquecer que a qualidade da inclusão se baseia na ativação de uma pluralidade de apoios humanos e materiais que fundamentam a ideia de inclusão (professores, amigos de sala, funcionários, mas também o espaço, a ajuda...). Ao mesmo tempo, tem sido considerado importante monitorar a mobilidade dos professores, evitando contínuas trocas de escolas ou a dedicação compartilhada com muitas instituições em modo concomitante, a fim de assegurar, tanto quanto possível, a continuidade de ensino;

- as práticas de ensino, a organização da classe e formação de professores. $\mathrm{Na}$ vida em sala, um papel é assumido pela formação da classe como um grupo, pela promoção de laços de cooperação entre os alunos, por meio da ativação de experiências que permitam que todos os alunos expressem suas habilidades, a partir de um modelo de ensino focado no estudante, o uso de uma pluralidade de fontes, materiais e recursos, o respeito pela sincronia e pelo ritmo individual. Cada um desses aspectos, que invocam uma aprendizagem ativa, requer conhecimentos e competências específicas por parte de todos os professores experientes no percurso de formação. Nos casos em que a participação é limitada a programas de treinamento e cursos de atualização de professores sobre a inovação do ensino, acaba sendo mais difícil e há uma tendência a prevalecerem modelos de ensino mais tradicionais. Assim, são menores as oportunidades de mudança potencial que a presença de alunos com deficiência traz e que ativam os processos de descoberta, de troca, de comparação, busca de estratégias educacionais apropriadas e ensino que devem estar dentro do planejamento normal da formação, contribuindo para o crescimento de todo o grupo;

- o envolvimento e a participação da família. Como já foi referido, existe a exigência constante e contínua, na legislação, da colaboração entre a escola e as famílias. Evoca-se o respeito mútuo das diferentes funções, de expressar e compartilhar fins educativos comuns. Essa perspectiva 
não pode favorecer o esquecimento de aspectos constitutivos da complexidade com que as famílias das pessoas com deficiência se confrontam. A difícil tarefa de um pai que, quando encontra situações de fragilidade e vulnerabilidade, vê amplificar toda uma gama de questões: a questão do cuidado e da educação, a gestão do relacionamento com os serviços, que em vários aspectos lida com o próprio filho, a reunião e discussão com diversos profissionais, a construção de uma teia de relações sociais que vão além dos muros da escola. Ainda neste caso, trata-se de trabalhar para evitar o máximo possível as situações de isolamento e marginalização das famílias, reconhecendo e fortalecendo a maioria de suas habilidades e potencialidades;

- a orientação e o plano de vida da pessoa com deficiência. A escola é chamada a fornecer uma formação que leve em conta características e inclinações pessoais dos alunos, enfatizando os traços peculiares. A orientação é a operação que permite identificar as atitudes e interesses das pessoas, criando as condições para uma escolha profissional o mais autônoma e motivada possível. A ação de orientação, em geral, implica um nível considerável de complexidade, pois pede que olhemos para a frente sendo bem ancorados ao presente. Escola, família e estudante advertem que, embora com diferentes modos relacionados a diferentes condições e funções, a importância de identificar um caminho que possa orientar sem fechar prenunciam novas oportunidades de crescimento, desenvolvimento, realização e aprendizagem. Os professores, envolvidos na difícil tarefa de promover e orientar são bem conscientes de como é importante à contribuição dos alunos que, no exercício de escolha, expressam habilidades de projetos, interesses e desejos. Mas, para muitos jovens, o foco do quem eu sou, o que eu quero e para onde vou não é uma tarefa simples e, nos casos em que os elementos de incerteza são somados a essas dificuldades, até mesmo os professores vivem com um peso maior o acompanhamento na transição e um tipo de escola para outro. A escola e a família desempenham um papel central, visto que podem contribuir significativamente para o foco das características particulares que os alunos expressam em diferentes contextos de vida. A necessidade de se chegar a uma forma mais abrangente de planejamento operacional que integre família, escola e aluno torna-se a base sobre a qual será construída uma hipótese de trabalho que possa detectar a adesão dos alunos e de suas famílias, permanecendo firmemente ancoradas em um plano da realidade. O referido relatório considera necessário que as famílias, os professores e os alunos tenham uma visão realista das diferentes oportunidades oferecidas. Destaca-se, assim, a tendência a trabalhar na perspectiva de uma assunção de responsabilidade compartilhada, que tem como objetivo a construção de um projeto de vida da pessoa que busca a maior autonomia possível e a sua participação ativa na vida social;

- A pesquisa, a documentação e o intercâmbio de boas práticas. Concluímos esta análise parcial de aspectos a serem monitorados com o des- 
taque acerca da necessidade de alimentar um circuito que encontra na pesquisa, na avaliação de processos e na documentação de boas práticas os recursos indispensáveis para uma leitura cuidadosa e consciente da escola italiana. Procura-se, assim, fazer com que o registro reflexivo e a participação dos atores sociais implicados sejam princípios orientadores para um processo que necessita ser analisado continuamente. A análise realista dos benefícios e dos obstáculos da inclusão escolar deve ser valorizada em uma realidade que assumiu o princípio da inclusão um valor pedagógico fundamental.

Recebido em 14 de março de 2014 Aprovado em 10 de maio de 2014

\section{Notas}

1 Para maiores detalhes relativos às configurações dos serviços e às alternativas de apoio inseridas na escola italiana, sugerimos o conhecimento de Di Pasquale e Maselli (1977).

2 Nota do Revisor: é importante esclarecer que o conceito integração não assumiu, no contexto italiano, o sentido similar àquele recorrente na literatura especializada brasileira. Durante vários anos integração foi o conceito predominante, mesmo quando era referido um processo de ampla adaptação contextual e de mudanças institucionais para favorecer a presença do aluno com deficiência. Desse modo, os conceitos de integração e inclusão devem ser identificados, no debate proposto pelo presente texto, como similares e contínuos.

3 Nota do Revisor: no contexto italiano, a difusão do termo Necessidades Educativas Especiais (Bisogni Educativi Speciali) ocorre apenas após 2010, diferentemente do observado na realidade brasileira que utilizou essa terminologia durante grande parte da década iniciada em 2001. Apesar dessa designação, no entanto, os indicadores numéricos mostram que, na Itália, permanece o predomínio de identificação do alunado como aquele que apresenta deficiência, pois o percentual de alunos é compatível com indicadores internacionais relativos a esse conceito.

4 Nota do Revisor: o professor de apoio é o docente com formação específica em educação especial, designado para trabalhar nas classes onde se encontram alunos com deficiência, como presença complementar àquela dos professores responsáveis pelas atividades curriculares. Essa atuação deve ocorrer, em modo predominante, na sala de aula comum.

\section{Referências}

ASSOCIAZIONE TREELLLE. Caritas Italiana. Fondazione Giovanni Agnelli. Gli Alunni con Disabilità nella scuola Italiana: bilancio e proposte. Trento: Erickson, 2011.

CANEVARO,Andrea.AllaRicerca DegliIndicatoridellaQualitàdell'Integrazione. In: IANES, Dario; TORTELLO, Mario. La Qualità dell'Integrazione Scolastica. Trento: Erickson, 1999.

CANEVARO, Andrea. La Famiglia con Disabilità "A Lezione". Entrevista Concedida a Giorgio Centa. 2013. Disponível em: <http://www.superando.it/2013/07/22/la-famiglia-con-disabilita-a-lezione-da-andrea-canevaro/>. Acesso em: 03 abr. 2014. 
CANEVARO, Andrea; MANDATO, Marianna. L'Integrazione e la Prospettiva Inclusiva. Roma: Monolite, 2004.

CELI, Fabio. Programmazione Individualizzata e Obiettivi della Classe: come collegarli? In: IANES, Dario; TORTELLO, Mario. La Qualità dell'Integrazione Scolastica. Trento: Erickson, 2000.

D’ALONZO, Luigi; IANES, Dario. L'integrazione Scolastica dal 1977 al 2007: i primi risultati di una ricerca attraverso lo sguardo delle famiglie. L'Integrazione Scolastica e Sociale, Trento, v. 6, n. 1, p. 15-29, fev. 2007.

DOVIGO, Fabio. Fare Differenze: indicatori per l'inclusione scolastica degli alunni con bisogni educativi speciali. Trento: Erickson, 2007.

IANES, Dario. La Speciale Normalità: strategie di integrazione e inclusione per le disabilità e i bisogni educativi speciali. Trento: Erickson, 2006.

ITÁLIA. Decreto Ministeriale, n. 226, de 27 de junho de 1995.

ITÁLIA. Ministero dell'Istruzione, dell'Università e della Ricerca. Linee Guida per l'Integrazione Scolastica Degli Alunni con Disabilità. Roma: 2009.

ITÁLIA. Ministero dell'Istruzione, dell'Università e della Ricerca. Indicazioni Nazionali per il Curricolo della Scuola dell'Infanzia e del Primo Ciclo di Istruzione, [S.1.] 2012.

MASELLI, Marina; PASQUALE, Giovanna di. A Integração Escolar dos Alunos Portadores de Deficiência na Itália. In: SILVA, Luiz Heron da; AZEVEDO, José Clóvis de; SANTOS, Edimilson Santos dos (Org.). Identidade Social e a Construção do Conhecimento. Porto Alegre: SMED/PMPA, 1997.

MIELE, Margherita. Didattica Integrata e Strategie di Intervento. Site Facolta' di Scienze della Formazione. [s.d.] Disponível em: <http://www.fasf.uniba.it/area_docenti/documenti_docente/materiali_didattici/97_Didattica_ integrata_e_strategie_di_intervento.pdf >.Acesso em: 12 dez. 2013.

PROVINCIA DI SONDRIO. Gruppo di Lavoro Interistituzionale Provinciale. Documento base sull' Integrazione Scolastica delle Persone con Disabilità in Provincia di Sondrio, 2007.

TILSTONE, Christina. Professional Development of Staff: steps towards developing polices. In: TILSTONE, Christina; ROSE, Richard. Strategies to Promote Inclusive Practice. Londres: Routledge Falmer, 2003.

Giovanna Di Pasquale é pedagoga, pesquisadora e professora na Universidade de Bologna (Scuola di Psicologia e Scienze della Formazione), integrante do Centro di Documentazione Handicap e Cooperativa Accaparlante - Bologna, com experiência em pesquisa, assessoria e formação de professores em diversas instâncias da gestão pública da Região Emilia-Romagna (Itália).

E-mail: context.sas@virgilio.it

Marina Maselli é pedagoga, docente junto à Universidade de Bologna (Scuola di Psicologia e Scienze della Formazione), com experiência em pesquisa, assessoria e formação de professores em diversas instâncias da gestão pública da Região Emilia-Romagna (Itália).

E-mail: marinamaselli63@gmail.com

Tradução e Revisão Técnica: Claudio Roberto Baptista 